\title{
RHINOLOGY
}

\section{Endoscopic treatment of choanal atresia and use of balloon dilation: our experience}

\section{Il trattamento endoscopico dell'atresia coanale e utilizzo delle dilatazioni mediante balloon: nostra esperienza}

\author{
Giovanni Carlo De Vincentiis ${ }^{1}$, Maria Laura Panatta ${ }^{1}$, Eugenio De Corso $^{2}$, Giulia Marini ${ }^{1}$, Alessandra Bianchi ${ }^{1}$, \\ Monica Giuliani ${ }^{1}$, Emanuela Sitzia ${ }^{1}$, Filippo Maria Tucci ${ }^{1}$ \\ ${ }^{1}$ UOC di Otorinolaringoiatria, Ospedale Pediatrico Bambino Gesù IRCCS Rome, Italy; ${ }^{2}$ UOC di Otorinolaringoiatria, \\ Fondazione Policlinico Universitario A. Gemelli IRCCS, Università Cattolica del Sacro Cuore, Rome, Italy
}

\begin{abstract}
SUMMARY
The aim of this study is to report our experience in surgical treatment of unilateral and bilateral choanal atresia. We describe the endoscopic surgical technique for creation of neochoanes and following repeating balloon dilation after surgery to stabilise the results. The study was carried out from December 2014 to December 2018, enrolling 46 patients who underwent surgery for choanal atresia at the Otolaryngology Unit of the Paediatric hospital Bambino Gesù: 17 with bilateral choanal atresia (Group A) and 29 with unilateral choanal atresia (Group B). All patients underwent transnasal endoscopic surgery. The incision of the mucosa was made with a cold and hot system (laser diode). The elimination of atresic plaque was possible thanks to the use of a drill; the calibration of the neo-choanes was carried out with the help of balloon dilation. No stent was used, and no patient underwent treatment with topical mitomycin. The first endoscopic follow-up was made 7 days after surgery with surgical curettage and a second balloon dilation 15 days after surgery to stabilise the new choanes. Further check-ups were suggested at 1 month after surgery and later based on individual progress. In group A, the average age for the first treatment was 10.4 days, and atresia was associated with other anomalies in $64 \%$ of cases. The therapeutic protocol led to a successful outcome in $82 \%$ of cases, with an average of 4.6 procedures per patient (range: $3-11$ ). In group B, the average age for the first treatment was 36.6 months, association with other anomalies was $27 \%$ of cases and the prevalent side was the right (11:6). We obtained surgical success in $85.7 \%$ of cases and the average number of endoscopic dilations was 3.5 (range: $3-7$ ). Transnasal endoscopic surgery is now considered the therapeutic goldstandard for both unilateral and bilateral atresia. Even if still used, post-surgery stenting can be avoided in our opinion; relapse is reduced with the use of balloon dilation, which, in our experience, is a valid aid in both primary atresia treatment and in cases of relapse.
\end{abstract}

KEY WORDS: choanal atresia, endoscopic sino-nasal surgery, balloon dilation

\section{RIASSUNTO}

Scopo di questo studio è quello di descrivere i risultati della nostra esperienza nel trattamento chirurgico endoscopico della atresia coanale e di illustrare in particolare il nostro protocollo che per mantenere pervio lo spazio coanale non prevede l'applicazione di uno stent ma dilatazioni endoscopiche mediante balloon ripetute nel post-operatorio al fine di stabilizzare il risultato chirurgico. Nel periodo compreso fra dicembre 2014 e dicembre 2018, abbiamo arruolato 46 pazienti affetti da atresia coanale e sottoposti a trattamento chirurgico presso l'Unità di Otorinolaringoiatria dell'Ospedale Pediatrico Bambino Gesù (17 con atresia coanale bilaterale e 29 con atresia coanale monolaterale), Tutti i pazienti sono stati sottoposti a chirurgia endoscopica transnasale. L'incisione della mucosa è stata realizzata con strumentazione a freddo e a caldo (laser a diodi). L'eliminazione della componente ossea è stata possibile mediante l'utilizzo di frese; la calibrazione delle neo-coane è stata eseguita con la tecnica di dilatazione mediante balloon. Nessuno stent è stato utilizzato e nessun paziente ha ricevuto trattamento topico con mitomicina. Il primo controllo endoscopico post-operatorio con eventuale dilatazione è stato eseguito 7 giorni dopo la procedura chirurgica. Una seconda valutazione endoscopica con medicazione e dilatazio-
Received: January 15, 2018

Accepted: April 22, 2019

Correspondence

Maria Laura Panatta

UOC di Otorinolaringoiatria, Ospedale Pediatrico Bambino Gesù IRCCS, via Torre di Palidoro snc, Fiumicino, Rome, Italy.

E-mail: marialaura.panatta@opbg.net

Funding

None.

Conflict of interest

The Authors declare no conflict of interest.

How to cite this article: De Vincentiis GC, Panatta ML, De Corso E, et al. Endoscopic treatment of choanal atresia and use of balloon dilation: our experience. Acta Otorhinolaryngol Ital 2020;40:44-49. https://doi.org/10.14639/0392$100 \mathrm{X}-1567$

(c) Società Italiana di Otorinolaringoiatria e Chirurgia Cervico-Facciale

\section{cc) (i) $(9)$}

This is an open access article distributed in accordance with the CC-BY-NC-ND (Creative Commons Attribution-NonCommercial-NoDerivatives 4.0 International) license. The article can be used by giving appropriate credit and mentioning the license, but only for non-commercial purposes and only in the original version. For further information: https:// creativecommons.org/licenses/by-nc-nd/4.0/deed.en 
ne è stata effettuata 15 giorni al fine di stabilizzare il risultato chirurgico. Ulteriori controlli sono stati pianificati ad un mese dall'intervento e $i$ successivi sulla base dei progressi del singolo paziente. In nessuno dei 46 pazienti trattati abbiamo osservato complicanze dopo i trattamenti endoscopici. L'età media dei 17 pazienti con atresia coanale bilaterale è stata di 10,4 giorni al momento del primo trattamento; nel 64\% dei casi l'atresia era associata ad altre anomalie. Il protocollo terapeutico ha garantito il raggiungimento di outcome soddisfacenti nell'82\% dei casi, con una media di 4.6 procedure realizzate per ogni paziente (range: 3-11). I 29 pazienti affetti da atresia monolaterale presentavano un'età media di 36,6 mesi al primo trattamento, una prevalenza di atresia monolaterale destra (11:6), un'associazione con ulteriori anomalie nel $27 \%$ dei casi. Abbiamo ottenuto una percentuale di successo dell'85,7\% con una media di 3,5 procedure per paziente (range: 3-7). La chirurgia endoscopica transnasale è attualmente considerata il gold standard terapeutico, sia per l'atresia monolaterale che bilaterale. A nostro parere, andrebbe evitato l'utilizzo di stent post-intervento, anche se ancora oggi vengono utilizzati; la recidiva è ridotta dall'utilizzo della dilatazione mediante balloon che, nella nostra esperienza, è un valido aiuto sia nel trattamento dell'atresia primaria che delle recidive.

PAROLE CHIAVE: atresia coanale, chirurgia con balloon

\section{Introduction}

Choanal atresia is a rare congenital malformation characterised by the lack of patency of communication between the third postero-inferior of the nasal cavity and nasopharynx. It can be unilateral or bilateral; its prevalence in the population is one in 5000-8000 live births with an incidence that is twice as high in females and with a predominance of the right side in unilateral atresia ${ }^{1-3}$.

Atresia may be associated with other congenital anomalies in over $50 \%$ of cases. The most common condition is the CHARGE syndrome, where the acronym is indicative of the association of coloboma with cardiac malformations (heart disease), atresia of the choanes, retard in development, alterations of the genital-urinary district and deafness and some other ear dysmorphism. Other associated congenital anomalies may be Crouzon and Di George syndromes, Treacher-Collins syndrome, Down syndrome and finally malformations which involve the mid-line of the face such as cleft palate, hypertelorism, development of meningocele, or encephalomeningocele ${ }^{4}$.

To date, its aetiology is unknown, even if Lee et al. found a significant association between the presence of bilateral choanal atresia and low levels of thyroxine serum ${ }^{5}$. Many embryological theories have tried to explain the genesis of this congenital malformation; the most accepted theory refers to the persistence of Hochstetter's nose and mouth membrane, as this membrane is re-adsorbed at the fifthsixth week of pregnancy to allow the choanal openings to develop, and its non-reabsorption favours the growth of an atresic plaque. Other theories suggest that this could be due to the anomalous persistence of mesodermic tissue, which results in an anomalous adhesion as well as anomalous migration of cells, also due to the presence of some local growth factors ${ }^{6}$.

Usually, $65-75 \%$ of cases show unilateral atresia, whereas bilateral atresia is less common ${ }^{7}$. The atresic plaque is completely osseous in $30 \%$ of cases and is mixed, osteo-membranous in the remaining $70 \%$. The bone surface is usually positioned at the back of the nasal cavity at the end of the septum bone, but the anatomic deformity is usually more complex, and the nasal cavity is reduced and funnel-shaped due to the presence of a medial procidentia of the pterygoid wing, whereas the widening of the vomer enhances an obstruction in the medial portion of the nasal cavity ${ }^{8}$.

In this manuscript, we report our experience on surgical treatment of bilateral and monolateral choanal atresia. We propose an endoscopic approach without using stents and suggest optimisation and stabilisation of the new choanes through the innovative use of balloon dilation. This approach was made possible by using sinuplasty balloon, which offers several advantages such as reduction of trauma in the surrounding tissues with minor complications, reduction of surgical time in the following revisions, an advantageous post-operation recovery and reduced hospitalisation of patients.

\section{Materials and methods}

\section{Study population and study design}

This is an observational study of 46 patients who were treated for choanal atresia at the "Ospedale Pediatrico Bambino Gesù" and who were followed for at least 12 months at our institution. Patients were enrolled between December 2014 and December 2018; 17 of 46 (36\%) had bilateral atresia (group A), and 29 of $46(64 \%)$ had unilateral atresia (group B). In group A (mean age: 10.4 days; range: 6-21 days; 7 male 7, 9 female), choanal atresia was associated with other syndromes in 64\% of cases (11 of 17) and specifically: 2 Down syndrome, 2 Franceschetti's syndrome, 3 CHARGE syndrome, 1 osteopetrosis, 1 deletion of chromosome 9, 1 Rapp-Hodkging syndrome and 1 patient with deletion of chromosome 8 . In group B (mean age: 2.6 yrs.; range 2-12 yrs., 12 male, 17 female) complex malformations were observed in 7 of 29 patients (24\%) and specifically: 5 Down syndromes, 1 costo-mandibular syndrome and 1 Di George syndrome.

At pre-operative evaluation all patients underwent nasal endoscopy and CT scan (Fig. 1) of the facial bone to confirm the presence of atresia and define the anatomic characteris- 


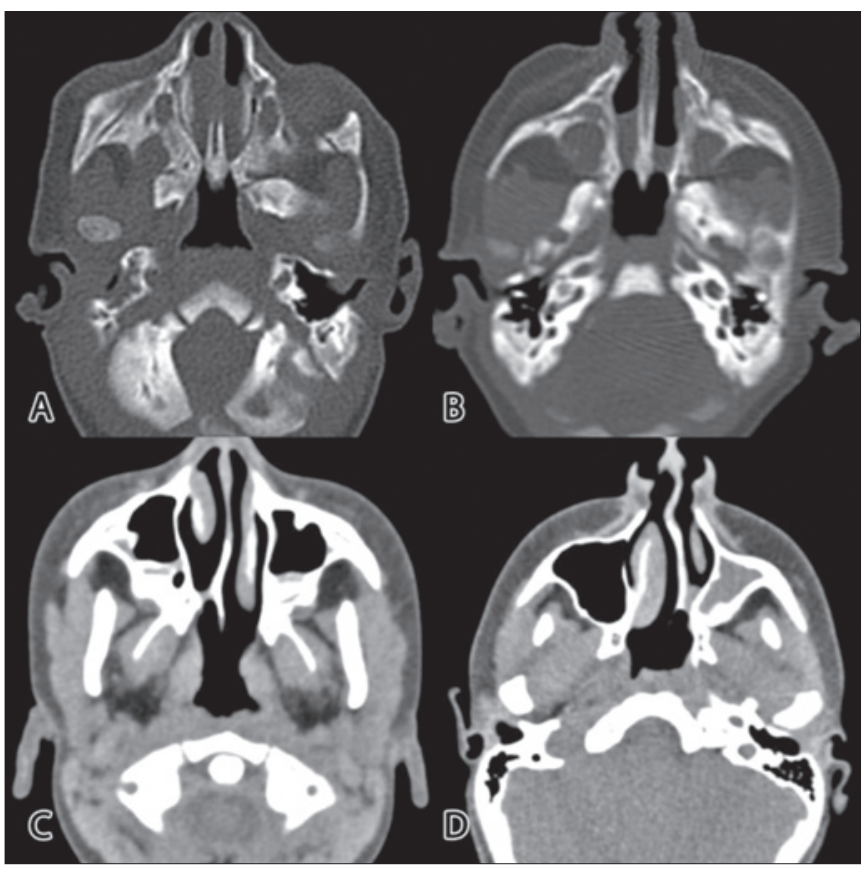

Figure 1. CT scan of bilateral (A-B) and unilateral choanal atresia (C-D).

tics of the malformation of the nasal cavities, as well as the nature of the atresic plaque and possible association with other anomalies.

\section{Surgical technique}

All patients underwent surgery under general anaesthesia with oral-tracheal ventilatory intubation. Inspection of the nasal cavities was done using a $0^{\circ}$ endoscope, with diameters from 2.7 to $4 \mathrm{~mm}$ (according to the patient's age), after nasal mucosa was decongested with cotton ball soaked in xylocaine $1 \%$ and 1:1000 adrenaline. All patients had osseous or osteo-membranous atresic plaques, whereas no case showed pure membranous forms. Access to the vomer was possible through definition of side hinge mucosal flaps, cut with or without the use of a laser diode, whereas elimination of the plaque was possible using a micro drill, by associating, in some cases, elimination of part of the vomer bone with forceps, so as to ensure a wider choanal caliber (Fig. 2).

In order to stabilise the neo-choanes obtained, they were dilated with the aid of balloon catheter (Acclarent Relieva Ballon Inflation Device), with a calibre from 7 to $10 \mathrm{~mm}$ (according to the patient's age) and with a length of $16 \mathrm{~mm}$. The catheters were applied in each nasal cavity for $20 \mathrm{sec}-$ onds, after being floated with saline solution, to 10-12 atmospheres by also positioning Hegar dilators of the fit calibre in the other cavity in order to avoid possible misplacement while carrying out the operation (Fig. 3).

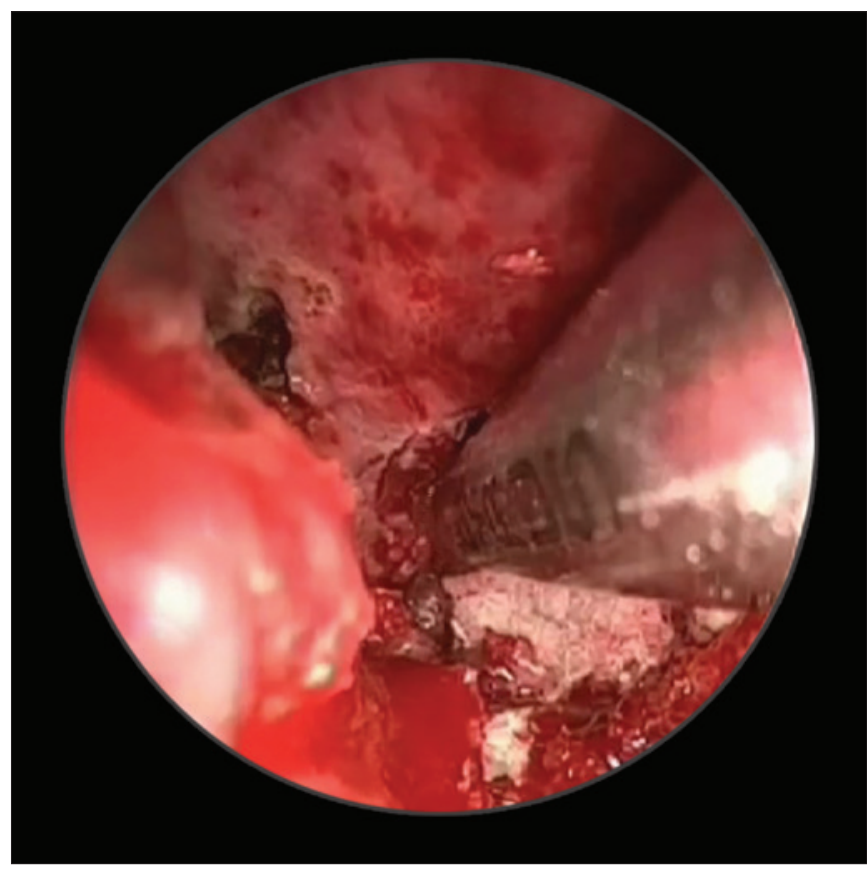

Figure 2. Elimination of choanal athresic plaque using a micro-drill.

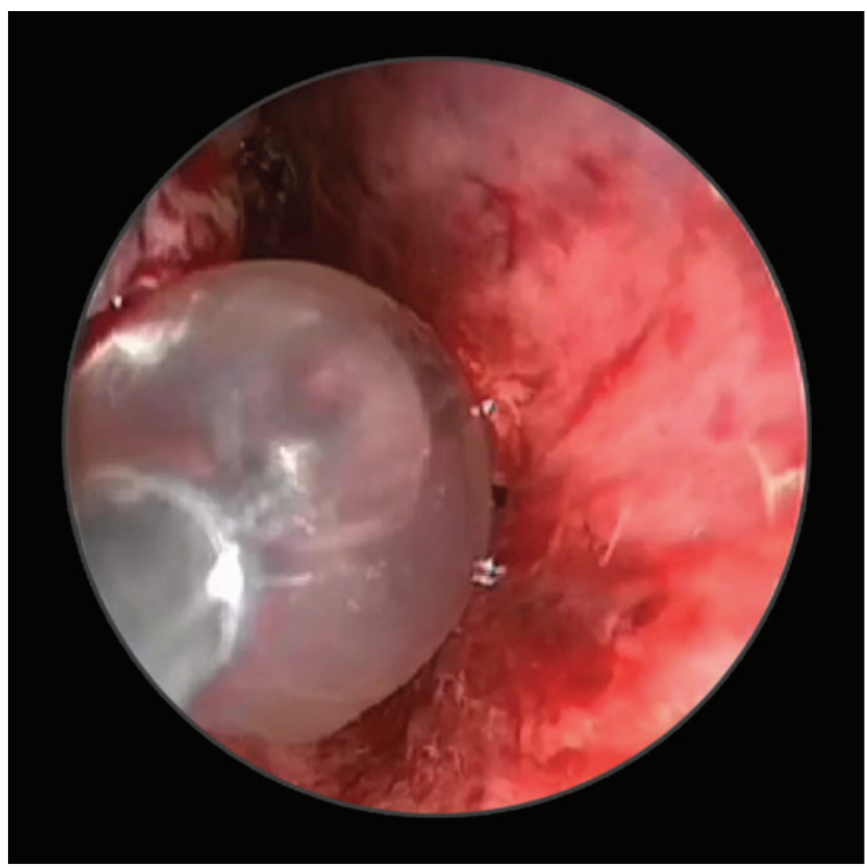

Figure 3. Endoscopic view of choanal balloon dilation.

No stent was applied and no nasal packing was necessary to control haemorrhage. All parents were instructed to perform several daily nasal irrigations during the post-surgical period, as well as topic inhalation of mometasone furoate, once daily, with $0.05 \mathrm{mg}$ for each cavity with nasal spray. 
After surgery two endoscopic follow-ups were planned under general anaesthesia at one and two weeks after surgery; granulation tissue was removed, whereas the presence of stenosis for excessive scarring was treated with new dilations, with radial drainage incisions made with cold systems so as to break the circular field lines which condition the restenosis. Nasal irrigations and topic inhalation were prescribed post-operatively for one month.

Further check-ups were planned at one month after surgery and later if required. The analysis of results is based on post-operative endoscopic check-ups. We assumed restenosis of the choane if a 50\% reduction of the neo-choanal space was observed. The minimum follow-up was 6 months and patients were observed for at least 12 months.

\section{Results}

In total, we treated 46 patients. Bilateral choanal atresia was most frequently associated with other syndromes than unilateral atresia, respectively $64 \%$ and $24 \%$ with a significant difference $(\mathrm{p}<0.05)$. In group A, average age at the first treatment was of 10.4 days of life (range 6 to 21 days). Surgery was safe in all cases; none of the patients needed post-surgery intensive care. Packing of the nasal cavity was not performed and stents were not applied. Topic steroids were prescribed for the following 30 days, associated with nasal irrigations with isotonic saline solution. All patients performed the planned endoscopic dilations in the first post-operative month. Surgery was successful in $82 \%$ of cases (14 of 17), and none had re-stenosis during followup. In three of 17 (18\%) patients we observed an early postoperative re-stenosis of choanal space that was evident at the first endoscopic follow-up at one month after surgery. In all cases the re-stenosis exceeded 50\% of the neo-choanal space. In these cases, we performed monthly dilation until success was obtained (in 2 of 3 cases). In these specific cases we performed from 3 to 11 dilations. The average of the dilation treatments in all series was 4.6 per patient, including the most difficult cases.

Following we provide a brief description of two of the challenging cases that failed in group A. The first was a patient suffering from Rapp-Hodgkin syndrome, which resulted in a higher number of procedures (11 treatments). This form of uncommon ectodermic dysplasia, due to a mutation in heterozygosity of the TP63 gene on chromosome $3 \mathrm{q} 28$, is characterised by abnormal development of the adnexal structures of ectodermic derivations (hair, teeth). The patient had large tendency towards post-surgery cicatricial stenosis that was inexplicable and for this reason we performed a genetic investigation that lead to the definition of the syndrome. The second case was suffering from osteopetrosis and was particularly difficult to treat. In this case, even after 10 treatments, we observed relapse of the stenosis due to abnormal re-ossification. Furthermore, the patient post-operatively developed severe anaemia that was not related to intra-operative blood loss. Post-operative clinical investigation revealed severe myelodysplasia requiring a bone marrow transplant that was effective.

Patients with unilateral atresia (group B) had better therapeutic outcomes, probably age-related, as the medium age for first treatment was 36.6 months. The average number of treatments per patient was 3.5. Surgery was successful in $93 \%$ of cases (27 patients of 29); none of these had re-stenosis during follow-up. In 2 of 29 (7\%) patients, both with an associated syndrome, the vomer bone had to be removed with construction of a monochoane. In particular, one of the patients suffered from a cerebro-costo-mandibular syndrome associated with a non-defined syndromic condition related to deletion of chromosome 10q26 with associated micro-duplication of chromosome 22q26.

\section{Discussion}

Choanal atresia was identified as nosological entity in the $18^{\text {th }}$ century, and the first surgical treatment was described in the literature by Emmert in 1851, through the use of a transnasal technique which, through a mere injection made by a provided trocar, assured patency of the choanal region. As can be imagined, the method was associated with a high percentage of restenosis 9 . From a clinical point of view, bilateral choanal atresia represents a specific medical rather than surgical emergency. A newborn has to breath through the nose, and this explains the so-called condition of "paradoxical cyanosis" that during a baby's cry is unexpectedly resolved thanks to momentary oral breathing, physiologically unknown to these patients. Considering such peculiarities, intensive care may be necessary, and surgery needs to be planned as soon as the clinical conditions of the patient allow for it. Patients with unilateral atresia have a different progress, diagnosis is often late and it is mostly related to the persistence of mono-lateral rhinorrhoea that is not responsive to therapy. Surgery has to be adequately planned to ensure correct cranial-facial development, thus preventing the recurrence of phlogosis in the rhino-sinus district. According to literature data, in our series we observed that bilateral choanal atresia was most frequently associated with other syndromes than monolateral choanal atresia $(64 \%$ versus $24 \%$; $p<0.05)$. Furthermore, in our series the diagnosis and age at first treatment were earlier in group A than in group B: 10.4 days versus 36.6 months, respectively.

The surgical approach for treatment of choanal atresia 
has always considered the use of transnasal, transseptal, transpalatal techniques, each of which has advantages and disadvantages, especially in relation to the patient's age and the complexity of the associated malformation. The aim of each intervention is to create patency of the choanal region in the most conservative way possible in order to avoid useless injuries to nearby structures whatever the approach. The transpalatal approach has undoubted advantages, especially in surgery, by offering a better visualisation of anatomic structures and consequently a lower risk of disorientation by the operator. Furthermore, it guarantees a lesser frequency of endocranial complications compared to a transnasal approach. This procedure, however, can modify the patterns of growth of the hard palate, the alveolar process of the maxillary and the bone and fleshy structures of the mid-line of the face; it can result in a higher risk of bleeding during surgery, other than in a changing incidence of lesions of the soft palate as explained in the literature ${ }^{10}$. The use of endoscopic techniques has radically changed surgery for choanal atresia, even if the rarity of this malformation and the random cases encountered explain why there is no standardised protocol for surgical technique, application of transchoanal stents and duration of such application ${ }^{11}$. Many advantages were brought with the application of endoscopic instruments, created to treat rhino-sinus inflammatory pathologies, when this instrument was used for diagnosis and treatment of choanal atresia, as this method represents a genuine revolution. It is a mini-invasive technique, much less traumatic, with the clear advantage that it provides high optimisation of the operative field, minimizing the risk of bleeding. This technique allows for correct inspection of these patients' noses, not only during surgery, but also after surgery, and is therefore commonly accepted as the preferred surgical method. Nevertheless, surgeons have to deal in the post-operative period with a high risk of re-stenosis due to local inflammation which promotes granulation tissue and scarring. For this reason, post-operative medications are very important to guarantee maintenance of the neo-choanal space over the months.

Some authors have suggested to use stents against the tendency of re-stenosis; choanal stents, in fact, are made of non-reactive material to allow stable and enduring surgical outcomes. Nevertheless, the need for postoperative stents has been debated for years. Riepl et al. ${ }^{12}$ supported the use of stents, describing a brief series of six cases of bilateral choanal atresia that underwent a transnasal endoscopic technique supported by balloon dilation. The balloon dilator was used to dilate the neochoanae and prevent restenosis. Nevertheless, they suggested the use of bilateral stents for 6 weeks after surgery, especially in very young patients, as a prerequisite to prevent early restenosis. In a recent
TRIO Best Practice monograph ${ }^{13}$, the authors recommended against the routine use of stents to avoid complications of stenting such as alar injury or infection. The review demonstrated that endoscopic transnasal repair of choanal atresia is a safe and effective surgery and that outcomes are good regardless of whether postoperative stents are used. Furthermore, the authors concluded that repair without stenting reduces the intensity of postoperative management and avoids the potential for stent-related complications.

The balloon dilation technique has been recently proposed as an alternative option to the use of stents. Balloon dilations with floatable catheters have been applied in many fields of our discipline, offering a good aid both in endoscopic functional surgery of the paranasal sinus and in the treatment of non-uniform sub-glottal and tracheal stenosis. The advantage of these devices is to apply radial strength, thus avoiding non-uniform solicitations on the stenotic surface, as well as the possibility to approach even very small diameters thanks to the presence of a guided system with minimum obstruction. Supporting the use of balloon dilation, Bedwell et al. ${ }^{14}$ described a series of 5 patients who underwent balloon dilation repair of choanal atresia or stenosis in conjunction with a transnasal endoscopic approach. All patients demonstrated choanal patency on last follow-up.

In this manuscript, we present our personal experience on endoscopic transnasal treatment of choanal atresia supported by balloon postoperative dilations. This is one of the largest series in literature conducted at a single centre. In a recent systematic review of the literature, Murray et al. ${ }^{15}$ demonstrated that there were significantly higher rates of treatment failure in patients who underwent delayed surgery for bilateral choanal atresia. Accordingly, in line with this supposition, in our series patients with bilateral choanal atresia were treated at an average age of 10.4 days, whereas those with a unilateral defect were treated at a mean age of 36.6 months. We further differentiate our results based on unilateral or bilateral involvement of stenosis. Treatment of monolateral choanal atresia usually may reach the best surgical outcome compared with bilateral involvement. In our protocol, an endoscopic approach plus repeated balloon dilation was successful in $82 \%$ of cases with bilateral atresia and in $93 \%$ of monolateral defects, with a statistically significant difference. Furthermore, the average number of treatments per patient was higher in bilateral choanal atresia than those with monolateral disease.

In conclusion, it is our opinion that this new approach to atresia represents a very good option in the surgical treatment of this pathology. Parents should be counselled that long-term success of choanal atresia repair may require revision surgeries to remove granulation tissue, inspect the 
choana and additional dilation. We sustain an approach that does not foresee the use of endonasal devices aimed at assuring the patency of the choanal area, since the inflammatory condition produced on the mucosa enhances cicatricial stenosis. We believe, therefore, that the use of stents is not motivated if not in exceptional cases.

\section{References}

1 Ibrahim AA, Magdy EA, Hassab MH. Endoscopic choanoplasty without stenting for congenital choanal atresia repair. Int J Pediatr Otorhinolaryngol 2004;74:144-50. https://doi.org/10.1016/j. ijporl.2009.10.027

2 Theogaraj SD, Hoehn JG, Hagan KF. Practical management of congenital choanal atresia. Plast Reconstr Surg 1983;72:634-40. https:// doi.org/10.1097/00006534-198311000-00007

3 Harris J, Robert E, Kallen B. Epidemiology of choanal atresia with special reference to the CHARGE association. Pediatrics 1997;99:363-7. https://doi.org/10.1542/peds.99.3.363

4 Assanasen P, Metheetrairut C. Choanal atresia. J Med Assoc Thai 2009;92:699-706.

5 Lee LJ, Canfield MA, Hashmi SS, et al. Association between thyroxine levels at birth and choanal atresia or stenosis among infants in Texas, 2004-2007. Birth Defects Res A Clin Mol Teratol 2012;94:951-4. https://doi.org/10.1002/bdra.23091

6 Hengerer AS, Strome M. Choanal Atresia: a new embriologic theory and its infleunce on sugical management. Laryngoscope 1982;92:913-21.

7 Dobrowski JM, Grundfast KM, Rosenbaum KN, et al. Othorhinolaryn- gic manifestations of CHARGE association. Otolaryngol Head Neck Surg 1985;93:798-803.https://doi.org/10.1177/019459988509300619

8 Harner SG, McDonald TJ, Reese DF. The anatomy of congenital choanal atresia. Otolaryngol Head Neck Surg 1981;89:7-9. https://doi. org/10.1177/019459988108900102

9 Keller JL, Kacker A. Choanal atresia, CHARGE association and congenital nasal stenosis. Otolaryngol Clin North Am 2000;33:1343-51. https://doi.org/10.1016/s0030-6665(05)70285-1

10 Flake CG, Ferguson CF. Congenital choanal atresia in infants and children. Ann Otol Rhinol Laryngol 1964;73:458-73. https://doi. org/10.1177/000348946407300216

11 Pasquini E, Sciarretta V, Saggese D, et al. Endoscopic treatment of congenital choanal atresia. Int $\mathrm{J}$ Pediatr Othorhinolaryngol 2003;67:271-6. https://doi.org/10.1016/s0165-5876(02)00386-5

12 Riepl R, Scheithauer M, Hoffmann TK, et al. Transnasal endoscopic treatment of bilateral choanal atresia in newborns using balloon dilatation: own results and review of literature. Int J Pediatr Otorhinolaryngol 2014;78:459-64. https://doi.org/10.1016/j.ijporl.2013.12.017

13 Bedwell JR, Choi SS. Are stents necessary after choanal atresia repair? Laryngoscope 2012;122:2365-6. https://doi.org/10.1002/lary.23381

14 Bedwell J, Shah RK, Bauman N, et al. Balloon dilation for management of choanal atresia and stenosis. Int J Pediatr Otorhinolaryngol 2011;75:1515-8. https://doi.org/10.1016/j.ijporl.2011.08.018

15 Murray S, Luo L, Quimby A, et al. Immediate versus delayed surgery in congenital choanal atresia: a systematic review. Int J Pediatr Otorhinolaryngol 2019;119:47-53. https://doi.org/10.1016/j. ijporl.2019.01.001 